\title{
Multi-Objective Optimal Sizing Design of a Diesel- PV-Wind-Battery Hybrid Power System in Colombia
}

\author{
Semaria Ruiz-Álvarez*ł, Jairo Espinosa* \\ * Departamento de Ingeniería Eléctrica y Automática, Facultad de Minas, Universidad Nacional de Colombia, 050041 \\ Medellín \\ (seruizal@unal.edu.co,jespinov@unal.edu.co)
}

‡ Semaria Ruiz, 050041, Tel: +57 44255092

Fax: +5744255260, seruizal@unal.edu.co

Received: 02.03.2018 Accepted:13.03.2018

\begin{abstract}
This paper proposes a design of an isolated hybrid microgrid using an iterative optimization method: the branch and cut algorithm. The Colombian community of Unguía, found in the state of Chocó, has been proposed for the microgrid design. The optimization objectives are the minimization of the grid operational costs and $\mathrm{CO} 2$ emissions, and ensuring $80 \%$ of load demand coverage. The elements considered in the microgrid design are: Two Diesel generators that already exists in community, a battery bank, photovoltaic panels and wind turbines. In addition a comparison between the designs obtained with the branch and cut algorithm and the software HOMER is performed for the Unguía community.
\end{abstract}

Keywords Batteries, Solar Energy, Wind Energy, Renewable sources, Diesel Generation, Microgrids, Optimization.

\section{Introduction}

Currently, most of the isolated electrical systems which operate with fossil fuel sources are being modified by hybrid schemes that include renewables sources, minimizing with this the environmental impact. Furthermore, the inclusion of renewables also improve the system availability [1], [2], and whether storage systems are included, the stability of the system is also improved [3]. That is why, several studies, as presented the in [4]-[6], had addressed the control and energy management issues, focus in isolated microgrids composed by renewable sources an several storage systems, which can be implemented in rural communities.

To carry out this modification in generation matrix, the optimization techniques are widely used as the renewable technologies can involve high investment costs compared with the conventional energy sources. Therefore, the proposed solutions need to be the most adjusted as possible in order to meet the energy requirements, and ensure the operation reliability. To solve the optimization problem there are several methods that explore the search space composed by the possible combinations of renewable, conventional sources and storage. Among them, the most used are described in [7], [8] and are:

- Enumeration techniques: they look for the elements size exhaustively, establishing a mesh or calculation frame and evaluating the cost function for each mesh point. Some design software, such as HOMER are based on these methods.

- Iterative methods: are mathematical procedures that generate approximate solutions to optimization problems. Some of the most commonly used iterative methods are: Linear Programming (LP), Quadratic Programming (QP) and Mixed Mixed Linear Programming (MILP).

- Artificial intelligence or heuristic methods: They use the heuristics to approximate the best solution to the optimization problem without guaranteeing that this optimum solution can be found [7]. Some of the most widely used artificial intelligence techniques for microgrid design are: Genetic algorithms (GA), particle swarm optimization algorithms (PSO), and ant colony algorithms (ACS).

Heuristic methods and enumeration techniques have the disadvantage that they can converge to local minimums of the optimization problem; therefore, many authors prefer the use of iterative techniques for the hybrid microgrids design, since, with it is possible to reach the optimum value of the problem or get close enough to it, with the use of mathematical tools. As the studies presented in [9]-[11]. In [9] a linear programming algorithm is used, to size the water pumping storage system in an isolated hybrid microgrid; In 
[10] and [11] an integer mixed linear programming is used to select the optimal location and size of renewable sources in an isolated microgrid for a non-interconnected rural community in Peru. Although on these studies technical and economic criteria are used in the elements siting and sizing approaches for isolated hybrid microgrids, the need for further researches involving more than one objective in the optimization cost function are set in [11]. Also in [12] is indicated that, in Colombia, microgrids could be the solution to the energy needs in non-interconnected to grid communities and in places where there are interruptions due to climatic phenomena such as El Niño.

In order to fill this gap, this paper proposes the design of an isolated hybrid microgrid using an iterative optimization method, taken as study case the Unguía Colombian community in Chocó department, as were also proposed in references [13], [14], but in this case the designs of the microgrid will be made taking into account 1 full year for the input data series, and the results obtained with the iterative method are compared with design found using the HOMER software, which uses an enumeration technique.

However, it is clarified that the optimization algorithm used in this paper is only usable for microgrids design purposes and not for control during the real systems operation.

This article is organized as follows: In Section II the methodology for microgrid design is proposed, in Section III the models used to represent the microgrid elements behavior are set, in Section IV the optimization mathematical approach is described. The Section V presents the study case characteristics and the results obtained with their analysis, are presented in Section VI.

\section{Proposed Microgrid Design Methodology}

The methodology described on this section is limited to microgrids with a common AC-bus topology, composed by: Diesel generation units, a battery bank, photovoltaic panels and wind turbines, as is shown in Fig.1.

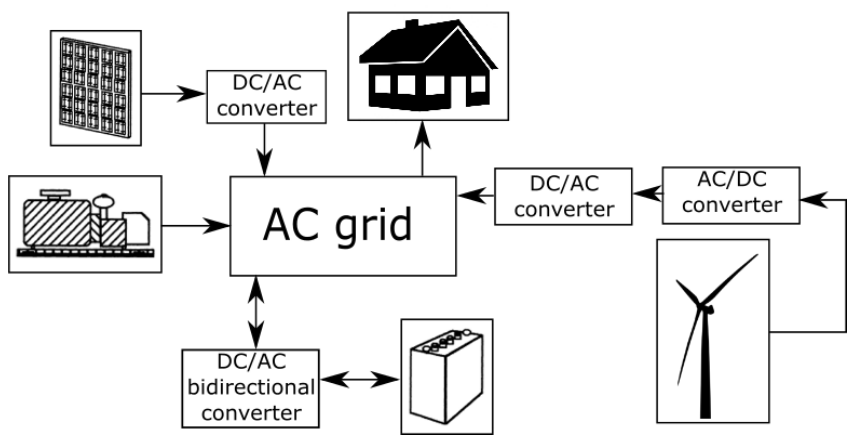

Fig. 1. Scheme of an isolated hybrid microgrid.

It is considered that the Wind-turbines are variable speed Wind-turbines; therefore an AC/DC-DC/AC power converter must be installed to interface the Wind generator with the grid and to transform the variable frequency power delivered by it into fixed frequency $\mathrm{AC}$ power. The photovoltaic modules have an inverter as interface device with the AC grid. And the batteries have a bidirectional converter, because they need absorb and deliver power to the grid.

The proposed design methodology is composed by the steps described in the flowchart of Fig.2.

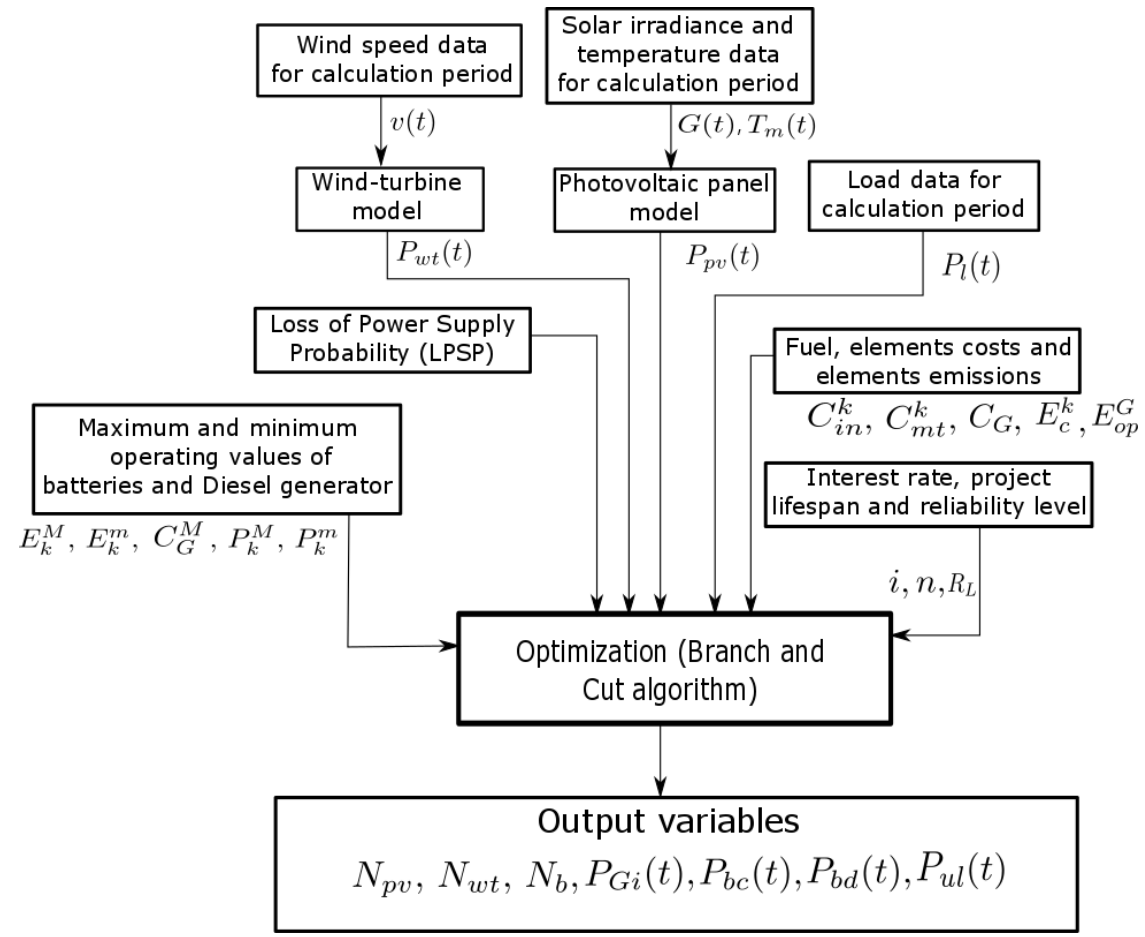

Fig. 2. Proposed methodology flow chart. 
This steps are described next: Initially, the weather variables: irradiance $G(t)$, wind speed $v(t)$, temperature $T_{m}(t)$, and the system load $P_{l}(t)$ are estimated or acquired, in such a way that time series can be set, with an hourly resolution, for these variables.

Subsequently, the dynamic models for the microgrid elements are chosen. The weather variables time series are taken as inputs for the renewable sources models; having as outputs the power delivered by them, at each time interval. Being $P_{w t}(t)$ the power related to the wind turbines and $P_{p v}(t)$ the related to photovoltaic panels.

In the case of dispatchable sources, such as Diesel generators; the power delivered will be programmed in order to supply the demand that cannot be covered by the renewable sources. Since the dispatchable sources have an almost permanent availability of energy resources, or much less uncertain than the renewable sources.

Then, renewable sources unit number, $\left(N_{w t}, N_{p v}\right)$ and the amount of batteries $\left(N_{b}\right)$ to be used in the design are established. Also the power dispatch variables are calculated; they are: the power delivered by Diesel $P_{G i}(t)$, the batteries charging or discharging power $P_{b}(t)$ and the unmet load $P_{u l}(t)$. To calculate this variables, an optimization process must be carried out But it is clarified that, in the operation stage of the microgrid, other management energy strategies as the described in [15]-[17] must be used in order to dispatch the power delivered by storage systems.

On the optimization process, the best value of the above decision variables is chosen from a set of feasible solutions that fills the defined reliability level $R_{L}$. To compare the solutions, a metric is established. This metric can be the system costs, the reliability, the emissions or a combination of them.

On this case the metric chosen is a combination of the total system cost and the total system emissions. The total system cost depends on the project interest rate $i$, lifespan $n$, initial investment cost of the $k$-th element $C_{i n}^{k}$, maintenance cost of the $k$-th element $C_{m t}^{k}$ and operational cost of Diesel generators $C_{G}(t)$. For his part, the total system emissions depends on the emissions generated by each element individually at the construction stage $E_{c}^{k}$ and the emissions generated by Diesel sources at the operation stage $E_{o p}^{G}$.

The algorithm used to solve the optimization problem is the branch and cut [18], which is part of iterative optimization techniques. In this method the branch and bound algorithm is complemented with the cutting plane algorithm, to restrict the execution of the relaxed problems every time that a branch of the search tree is explored.

\section{Elements Modelling}

In this section only models for batteries and Diesel generators are discussed in detail. The remaining microgrid elements are taken from current literature. Wind turbines, batteries and Diesel generators are modeled as presented in reference [19] and the photovoltaic panels use the model set in [20].

\subsection{Batteries}

The energy in the battery $\left(E_{b}(t)\right)$ meets the equation (1) [21] at each hour $t$; assuming that the charging efficiency is 1. Considering a battery bank, where each battery has the same level of charge as the others. And taking into account that the charge and discharge power are represented by the same variable $P_{b}$, which takes positive values when the batteries are charging and negatives when the batteries are discharging.

$$
E_{b}(t+1)=E_{b}(t)\left(1-\gamma_{s d}\right)+P_{b}(t)
$$

\subsection{Diesel generator}

The power delivered to the grid by the diesel generator $\left(P_{G}(t)\right)$ is given by equation (2).

$$
P_{G}(t)=\eta_{D G} P_{G i}(t)
$$

Being $\eta_{D G}$ the efficiency of the generators and $P_{G i}(t)$ the real power generated by the Diesel units. [20]:

The Diesel fuel consumption $G_{d f}$ is given by equation (3)

$$
G_{d f}(t)=A_{D} P_{G}^{M}+B_{D} P_{G i}(t)
$$

Where the coefficients $A_{D}$ and $B_{D}$ have the next values: $\left.A_{D}=0.0845[1 \cdot \mathrm{kW}\}\right]$ and $B_{D}=0.2461 \quad[1 \cdot \mathrm{kW}]$. The first coefficient $A_{D}$ is a proportionality constant that relates the power supplied with the fuel consumption. The second coefficient $B_{D}$ is a marginal consumption that exists even when the generator does not deliver power to the grid because it is on; it is a value proportional to the nominal power of the generator.

\section{Optimization Formulation}

In references [13], [14] an optimization approach was already proposed for the design of an isolated hybrid microgrid composed by Diesel, PV, wind and several storage systems. In this case, this approach is taken into account again, and for the sake of completeness, this optimization approach is described, as follows.

\subsection{Objective function}

As was established before, the metric to compare the solutions, also called objective function, have two terms: the yearly total system cost $\left(C_{T}\right)$ and the total system emissions $\left(E_{T}\right)$. To obtain an analytic expression that takes into account the importance degree of each term, the weighted sum method is applied [22]. On these, a weight factor is assigned to each objective as equation (4) indicates.

$$
f=C_{T}+w_{E} E_{T}
$$

where a unitary weight was assigned to the yearly total system cost; an weight factor of $w_{E}$ was assigned to the total emissions. The value of $w_{E}$ was chosen as 8.49 [USD/tCO $C_{2}$ ] 
which correspond to the annual average emissions cost, set by Sendeco [23], for the European Union in 2015.

\subsubsection{Total system cost}

The yearly total system cost is composed by: the annualized investment cost $C_{i n}$, which corresponds to the annual payment that must be made for the acquisition of new equipment at the initial stage of the project; the total annual maintenance cost of microgrid elements $C_{m t}$ and the cost associated with the fuel spend by the diesel generators $C_{G}$.

$$
C_{T}=C_{i n}+C_{m t}+C_{G}
$$

Where, the cost associated with Diesel generation $C_{G}$ is given by equation (6).

$$
C_{G}(t)=\sum_{t=1}^{N}\left[G_{d f}(t) C_{d f}(t)+G_{l}(t) C_{l}\right]
$$

Being $N$ the hours taking into account in the design horizon. In this case a year is considered, hence the value of this variable is $8760 . G_{d f}(t)$ the consumption of the diesel fuel at each hour of the year, $C_{d f}(t)$ the fuel cost, which varies for each month of the year and is obtained from Table I, $C_{l}$ is the cost of the lubricant which is 4.39 [USD/gal] as is indicated in [23], that value is assumed for the whole year 2015, and $G_{l}(t)$ represents the diesel generator's lubricant expense, which is related to fuel consumption by the following expression [24]:

$$
G_{l}=0.001226 P_{G i}
$$

Table 1. Appearance diesel fuel price for Unguía community [USD/gal].

\begin{tabular}{|c|c|c|c|c|c|c|c|}
\hline Month & Jan & Feb & Mar & Apr & May & Jun & Jul-Dec \\
\hline Fuel price & 3.12 & 3.07 & 2.96 & 2.96 & 2.96 & 3.00 & 3.02 \\
\hline
\end{tabular}
as:

The annualized initial investment cost $\left(C_{i n}\right)$ is calculated

$$
C_{i n}=\frac{i(1+i)^{n}}{(1+i)^{n}-1}\left[\sum_{k \in v} N_{k} C_{k}+C_{T r}+C_{r e}\right]
$$

where, the variables $N_{k}$ and $C_{k}$ indicate the units number and the initial investment cost the $k$-type element, with $k \in \eta=\{p v, w t, b\}$.

The term $\left[i(1+i)^{n}\right] /\left[(1+i)^{n-1}\right]$ is called the Capital Recovery Factor (CRF), and indicates the amount of equal payments in $n$ years in such a way that the present value of these payments is equivalent to the total payment of the initial investment in the present. In this case a debt repayment time of $n=20$ years is taken, and an annual cash interest rate of $i=5 \%$ it is considered.

In addition, the annualized initial investment cost also includes the replacement $\operatorname{cost} C_{r e}$ for elements with a lifespan less than 20 years, which are: batteries, inverters of photovoltaic panels and inverters of batteries; and the land usage price. The equation (9) indicates the calculation of these replenishment costs.

$$
C_{r e}=N_{b} C_{r e}^{b}+N_{b} C_{r e-c o}^{b}+N_{p v} C_{r e-i n}^{p v}
$$

where, $C_{r e}^{b}$ is the battery replacement $\operatorname{cost}, C_{r e}^{b}$ is the battery converter replacement cost and $C_{i n}^{p v}$ is the photovoltaic panel inverter replacement cost.

The initial investment of the Diesel generators is not included in the system costs as it is considered that Diesel generation already exists on the proposed microgrid location.

The cost associated with the land occupied by renewable sources and batteries $\left(C_{T r}\right)$, is calculated by the following expression:

$$
C_{T r}=i p s\left(\sum_{k \in v} N_{k} A_{k}\right)
$$

where, ips is the land price index $\left(0.05\left[U S D / m^{2}\right][25]\right)$, and $A_{k}$ is the land occupied by the $k$-type element.

The yearly maintenance cost of the elements $C_{m t}$ is given by the next expression:

$$
C_{m t}=\sum_{k \in V} N_{k} C_{m t}^{k}+C_{m t}^{D G}
$$

Being $C_{m t}^{k}$ the maintenance cost of the $k$-type element.

\subsubsection{Total CO” system emissions}

The total $\mathrm{CO} 2$ system emissions are composed by the emissions generated on the elements construction stage and the emission generated on the Diesel generators operation stage, as shows the Eq. (12).

$$
E_{T}=\sum_{k \in v} N_{k} P_{k}^{M} E_{c}^{k}+\left[\sum_{t=1}^{N} E_{o p}^{G} G_{d f}(t)\right]
$$

The variables $P_{k}^{M}$ indicate the maximum power given by the element of k-type, the variables $E_{c}^{k}$ are the emissions generated in the construction stage of the k-type element, and the variable $E_{o p}^{G}$ represents the emissions generated by the Diesel fuel combustion.

\subsection{Constraints}

Taking into account the previous models, the power delivered by the renewable sources and diesel $\left(P_{\text {gen }}\right)$ is given by equation (13).

$$
P_{g e n}(t)=N_{w t} P_{w t}(t)+N_{p v} P_{p v}(t)+P_{G}(t)
$$




\subsubsection{Operational constraints}

The power balance indicated in (14) must be met for all the time intervals.

$$
P_{l}(t)=P_{g e n}(t)-P_{b}(t)+P_{u l}(t)
$$

The number of photovoltaic panels, wind turbines, batteries, the power delivered by diesel generator and the unmet load must be positive quantities.

$$
\begin{gathered}
N_{p v} \geq 0 ; N_{w t} \geq 0 ; N_{b} \geq 0 ; \\
P_{G}(t) \geq 0, P_{u l}(t) \geq 0
\end{gathered}
$$

The energy in the battery bank must be maintained within the permitted operating limits. $E_{b}^{m}$ is the minimum of energy or the lowest value in each battery, and $E_{b}^{M}$ is the maximum value.

$$
N_{b} E_{b}^{m} \leq E_{b}(t) \leq N_{b} E_{b}^{M}
$$

The charge or discharge power of the battery bank and the power delivered by the Diesel generator must be within the permitted operating limits. Moreover, the unmet load must be lower than the load demand.

$$
\begin{gathered}
0 \leq P_{b}(t) \leq N_{b} P_{b}^{M} ; \quad 0 \leq P_{G i}(t) \leq P_{G}^{M} \\
0 \leq P_{u l}(t) \leq P_{l}
\end{gathered}
$$

\subsubsection{Reliability constraints}

A reliability level $R_{L}$ is defined as a restriction of the optimization problem. $R_{L}$ is the ratio of the total unmet load to the total load demand over a given time period, thus the system has the duty of supplying as minimum the $R_{L} \%$ of the load demand in the time taken for the design; as is indicated in equation (18).

$$
\sum_{t=1}^{N} P_{u l}(t) / \sum_{t=1}^{N} P_{l}(t) \leq R_{L}
$$

A $R_{L}$ of 0 means the load will be always satisfied, and the $R_{L}$ of 1 means that the load will never be satisfied.

It is emphasized that all the above restrictions are linear.

\section{Microgrid Location and System Parameters}

To propose the microgrid location, the study performed in [26] was taking into account. In it a feasibility analysis for the location of hybrid electric systems in Noninterconnected areas in Colombia was performed. Giving as result that in the Unguía community, the alternative of energization with photovoltaic panels presents generation costs lower than the maximum costs of providing the service, while the wind alternative presents comparable generation costs; therefore a system with both generation alternatives is proposed. On this paper a battery bank is also added.
The location of the Unguía - Chocó community is illustrated in Fig.3.

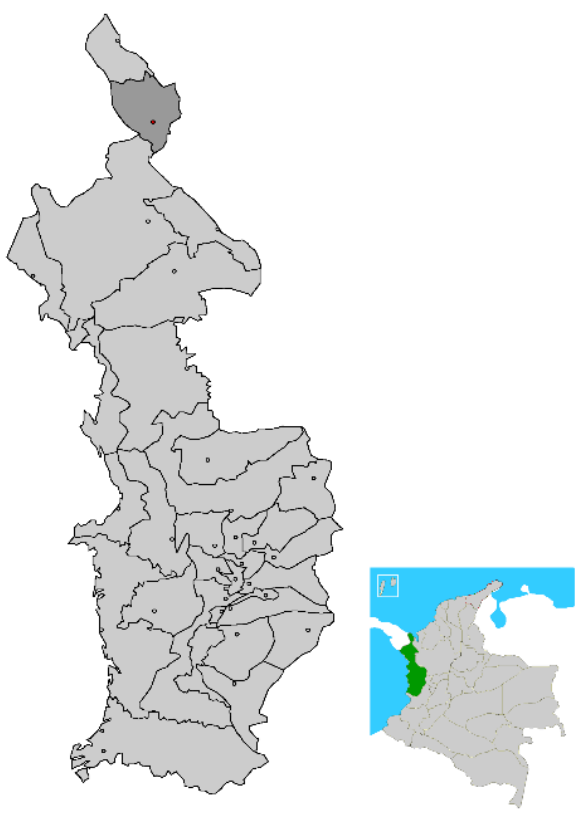

Fig. 1. Unguía community location.

The weather variables and the load demand will be taken for the 2015 year to perform the microgrid design.

The wind speed and temperature data were provided by [27], [28], but the measures have gaps in some hours, which were filling assuming a probability distribution for the data. For the wind speed a Weibull distribution was assumed, for the temperature a Kernel distribution was used.

On the other hand, the radiation data for the Unguía community, were taken from the NASA database [29] through the software HOMER ${ }^{\circledR}$ giving the location of the Unguía community in the HOMER interface, where the annual solar radiation averages are found, and through the application of the Graham algorithm [30] the hourly data of solar irradiance in the horizontal surface are synthetically generated. However, to access to the climatological database of HOMER, a paid license is required; therefore, other free databases could be used, such as the provided by the Columbia University in [31], in order to obtain the average monthly radiation data, and through the Graham algorithm the hourly data can be estimated for each day.

The load demand of the Unguía community was provided by [32].

A specific type of photovoltaic panel, wind turbine and battery was chose in order to perform the optimal design of the microgrid, the element parameters were taken from [33].

\section{Results and Analysis}

The mixed integer optimization was solved with the Gurobi solver in Matlab, which uses an iterative optimization technique, the Branch and Cut algorithm. 
The elements number obtained with the Branch and Cut algorithm and using software HOMER are show in Table II.

Table 2. Optimization results.

\begin{tabular}{|l|l|l|}
\hline Item & $\begin{array}{l}\text { Branch and cut } \\
\text { Algorithm }\end{array}$ & HOMER \\
\hline $\mathbf{N}_{\mathrm{wt}}$ & 20 & 0 \\
\hline $\mathbf{N}_{\mathbf{p v}}$ & 506 & 694 \\
\hline $\mathbf{N}_{\mathbf{b}}$ & 36 & 0 \\
\hline $\begin{array}{l}\text { Objective function } \\
\text { value [USD] }\end{array}$ & $\$ 1,090,600$ & $\$ 1,144,600$ \\
\hline $\begin{array}{l}\text { Diesel generation } \\
\text { usage (respect to total } \\
\text { generation) [\%] }\end{array}$ & 37.80 & 71.74 \\
\hline
\end{tabular}

The block diagram of the microgrid implemented in HOMER is shown in Fig. 5.

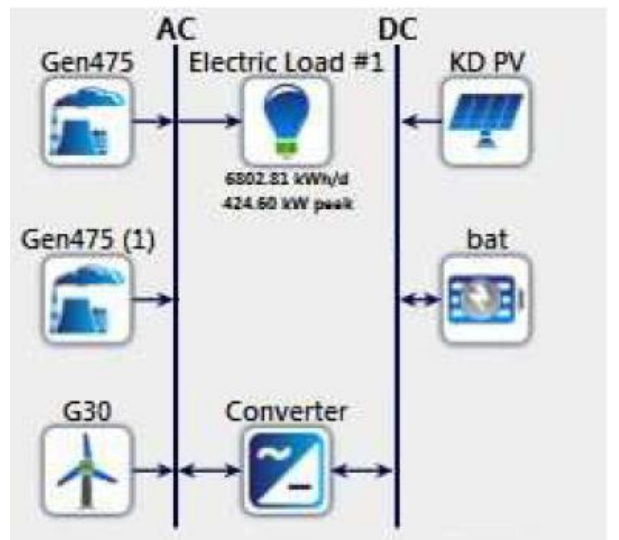

Fig. 5. Block diagram of microgrid implemented in HOMER

The microgrid implemented in HOMER is composed by the two Diesel generators of $475 \mathrm{kVA}$ that already exists at the Unguía community, photovoltaic generation with solar panels of $1 \mathrm{~kW}$, wind turbines of $30 \mathrm{~kW}$, a battery bank composed by $15 \mathrm{kWh}$ batteries; power converters of 1000 $\mathrm{kW}$, whose investment, maintenance and replacement costs where set in $\$ 0$, as the costs of power converters were assigned to each element that will require of them; and finally there is a block for the system load, in which were imported the data of the Unguía community consumption. Furthermore it is indicated that, in HOMER, it was assigned a cost to each element which correspond to the same cost in the objective function indicated in eq. (4).

The averages of the obtained power dispatch are presented on Fig.5 and Fig.6.

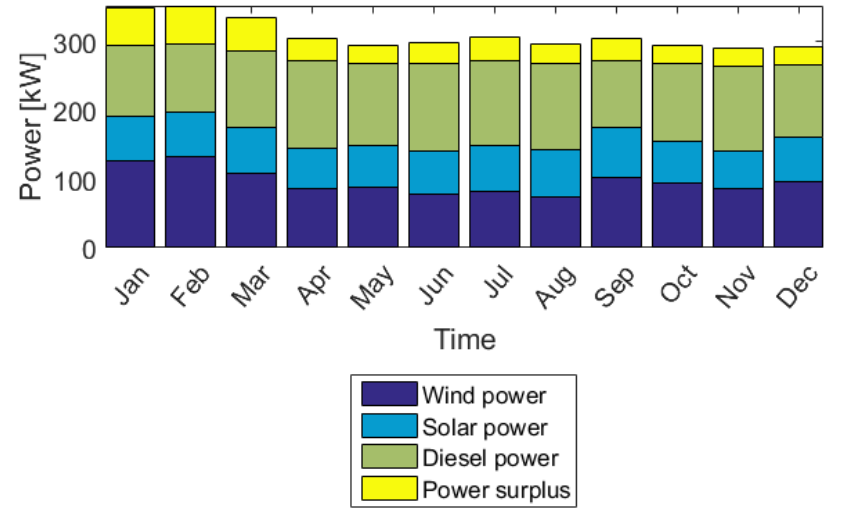

Fig. 5. Monthly average power generated by renewable sources and Diesel generator, for solution obtained with Branch and Cut algorithm.

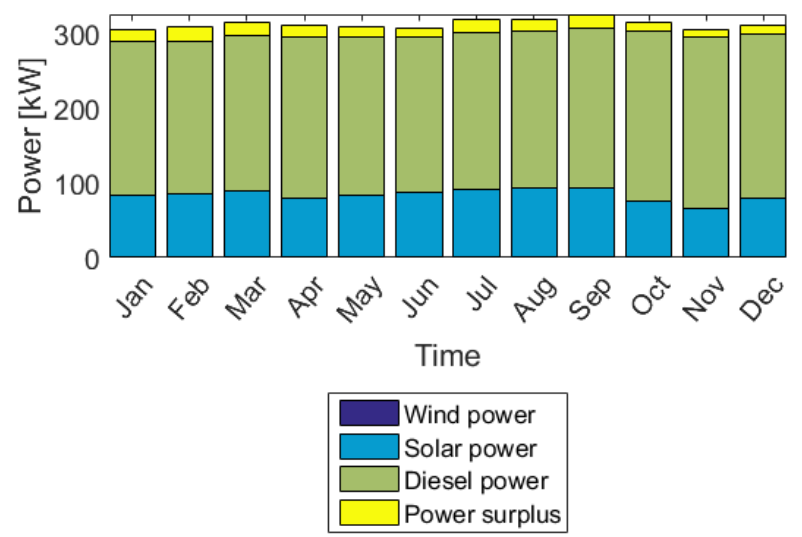

Fig. 6. Monthly average power generated by renewable sources and Diesel generator, for solution obtained with HOMER.

Additionally, two days, March 1st and 2rd are taken as example to illustrate the behavior of the power dispatch variables.

Fig.7 and Fig.9 shows the total power generated renewable sources and Diesel, the load demand and surplus power for the system obtained with Branch and Cut algorithm and HOMER, respectively. On the other hand, Fig.8 illustrates the energy in the battery bank. 


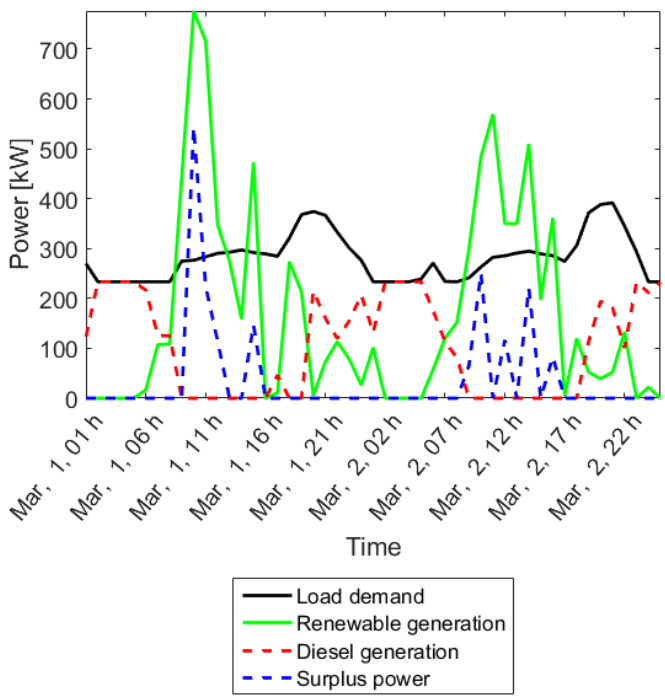

Fig. 7. Power delivered by renewable sources and total generation in March days, for solution obtained with Branch and Cut algorithm.

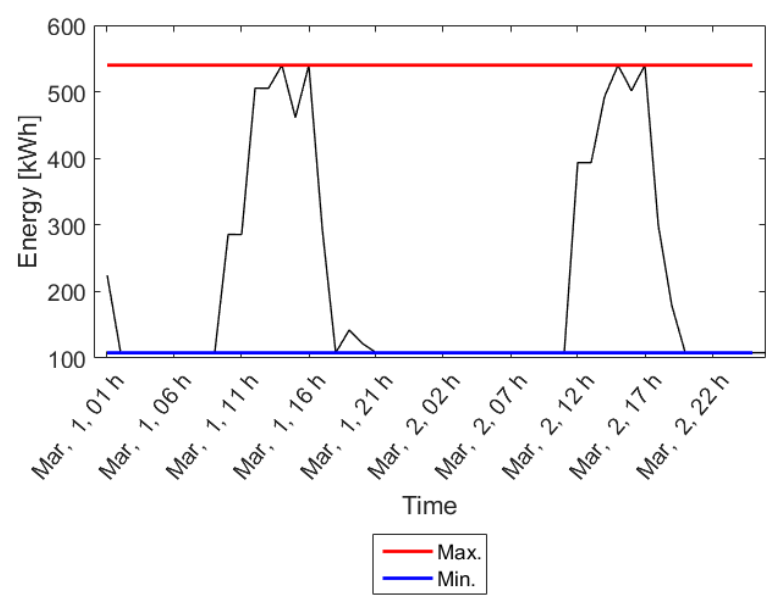

Fig. 8. Energy on battery bank in March month.

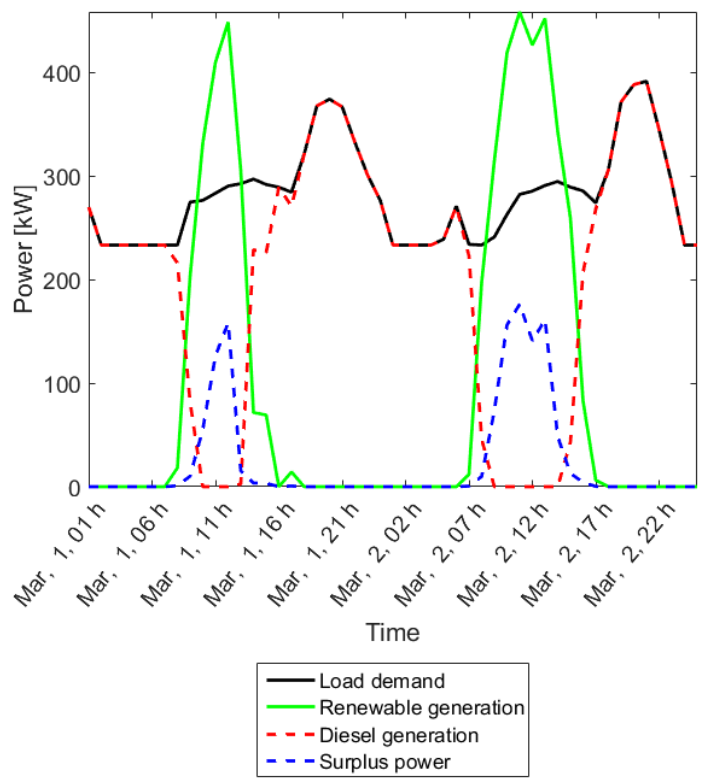

Fig. 9. Power delivered by renewable sources and total generation in March days, for solution obtained with HOMER.
On Fig.7 it can be seen that in some hours the renewable generation overlap the load curve. This excess of generation goes to the storage system, as can be appreciated on Fig.8 on hours: 8:00 to 13:00 and 15:00 at March 1st; 9:00 to 14:00 at March 2rd. Furthermore, a part of the excess of energy isn't used for the system; this wasted energy which is called surplus energy.

On Fig.5 and Fig.6, it can be seen that the source that most quantity of energy supplies to supply the demand is the Diesel. In the case of deign obtained with Branch and Cut algorithm the generation is composed $37.80 \%$ by Diesel, $37.24 \%$ by wind generation and $24.96 \%$ by solar generation. And the surplus energy correspond to the $7 \%$ of the total generation. For design obtained with HOMER the generation is composed $71.74 \%$ by Diesel and $28.26 \%$ by solar generation. And the surplus energy correspond to the $4.88 \%$ of the total generation. Besides, in Table II can be observed that HOMER design does not consider wind turbines and batteries, and not present unmet load.

Thus, it can be concluded that the HOMER design present a high dependence on Diesel as can be seen on Fig.8, therefore, its emissions are the highest and its support in installed capacity is the lowest; hence, the system will be more sensitive to variations in the supply schedules or costs of Diesel fuel. On the other hand, the HOMER design present a higher cost than the design obtained with Branch and Cut algorithm. This is due to the solution obtained with Branch and Cut is reclined over the reliability constraint for the reliability level $R_{L}$ shown in equation (18), since the demand supplied is exactly $80 \%$, and in the case of HOMER the solution is not over this constraint as the supplied demand is $100 \%$. Hence, the costs that can be saved in a system that does not supply $100 \%$ of the energy, are not reflected in the solution found by HOMER. Furthermore, the solution with the branch and cut algorithm is cheaper because it makes use of wind turbines and batteries, as is shown in Fig.5 and Fig.8; even though in this solution more energy is wasted than in the HOMER solution.

Therefore, it can be concluded that for the wind conditions given in the Unguía community it is profitable to install wind turbines, although not all its generated power is used, as can be seen in Fig.6 at hours 11:00, 12:00 and 15:00 on March 1st. And it is necessary to install a battery bank that stores a portion of the renewable generation. Since if all the remaining power is stored, storage would be more expensive.

\section{Conclusions}

This article presents a methodology approach to design hybrid isolated microgrids using an iterative optimization method: Branch and Cut, taking as design time horizon a year. A hybrid microgrid design for the Colombian rural community of Unguía in Chocó department, was used as study case to apply the proposed methodology. Furthermore the obtained solution with Branch and Cut algorithm was compared with the solution obtained with HOMER software, for the same study case. 
From the obtained results it was found that the Diesel is the most used energy source, as the renewable inclusion is too expensive yet to compete with Diesel generation. Although the design obtained with the Branch and Cut algorithm, that integrates renewable sources, gives an annual thrift of 53,976 USD on the objective function, with respect to the existing system composed only by Diesel generation, and also grant a cover of $80 \%$ of the estimated load demand, whereas the existing system only covers the $63.83 \%$ of it.

On the other hand, design obtained with HOMER presents a higher cost and Diesel usage than design obtained with Branch and Cut, as HOMER only considers a system with Diesel and Solar generation, which could lead to a lack in the demand supply due to maintenance of Diesel generators or difficulties on bring the Diesel fuel to the Unguía municipality.

In addition, it can be concluded that, although the same costs and the same climatological data were used to design the microgrid of Unguía with HOMER and with the proposed algorithm, the design that reached the lowest cost was the obtained with proposed algorithm, since it employs a deterministic iterative optimization method, the Branch and Cut algorithm, whose solution is reclined over the constraint of the reliability level; which means, the solution found with the proposed method is not only a feasible solution, as is the case of the design found with HOMER, but it is also the cheapest possible, keeping in mind the minimum energy that must be supplied by the system. .

However, it is emphasized that, unlike HOMER, the proposed method requires prior knowledge of the climatological variables at the micro-grid design site, and the model of photovoltaic panels used does not allow to observe the variations of the power produced by the panels when the tilt and the azimuth angles change, which is allowed by HOMER

\section{Acknowledgements}

The authors would like to thank Colciencias for its formative program Jóvenes investigadores, convocation N.645 of 2014 and N.706 of 2015.

\section{References}

[1] A. Abdulkarim, S. M. . Abdelkader, D. J. . Morrow, A. J. Falade, A. U. . Lawan, and H. R. . Iswadi, "Effect of weather and the hybrid energy storage on the availability of standalone microgrid," International Journal of Renewable Energy Research., vol. 6, no. 1, pp. 189-198, 2016.

[2] Y. Allahvirdizadeh, M. Mohamadian, and M. Haghifam, "Study of Energy Control Strategies for a Standalone PV/FC/UC Microgrid in a Remote Area", International Journal of Renewable Energy Research., vol. 7, no. 3, 2017.

[3] E. Hossain, R. Perez, and R. Bayindir, "Implementation of hybrid energy storage systems to compensate microgrid instability in the presence of constant power loads," International Conference on Renewable Energy Research and Applications ICRERA, pp. 1068-1073, 2016.

[4] A. Venkataraman, A. I. Maswood, S. N. Rahman, and O. H. P. Gabriel, "A novel maximum power point tracking algorithm for a stand-alone unity power factor wind energy conversion system," International Conference on Renewable Energy Research and Applications ICRERA, pp. 109-114, 2013.

[5] F. Girbau-Llistuella, A. Sumper, R. Gallart-Fernandez, and V. Buehner, "Operation of rural distribution grids with intermittent generation in connected and island mode using the open source EMS solver SCIP," International Conference on Renewable Energy Research and Applications ICRERA, pp. 983-988, 2015.

[6] T. T. Sepulveda and L. Martinez, "Optimization of a Hybrid Energy System for an Isolated Community in Brazil," International Journal of Renewable Energy Research., vol. 6, no. 4, pp. 1476-1481, 2016

[7] C. Gamarra and J. M. Guerrero, "Computational optimization techniques applied to microgrids planning: A review," Renewable \& Sustainable Energy Reviews, DOI: $10.1016 /$ j.rser.2015.04.025, vol. 48, pp. 413-424, 2015.

[8] Y. Tan, L. Meegahapola, and K. M. Muttaqi, “A review of technical challenges in planning and operation of remote area power supply systems," Renewable \& Sustainable Energy Reviews, DOI: 10.1016/j.rser.2014.07.034, vol. 38, pp. 876-889, 2014.

[9] P. D. Brown, J. a. Peças Lopes, and M. a. Matos, "Optimization of pumped storage capacity in an isolated power system with large renewable penetration," IEEE Transactions on Power Systems, DOI: 10.1109/TPWRS.2008.919419, vol. 23, no. 2, pp. 523531, 2008.

[10]L. Ferrer-Martí, R. Pastor, G. M. Capó, and E. Velo, "Optimizing microwind rural electrification projects. A case study in Peru," Journal of Global Optimization, vol. 50, no. 1, pp. 127-143, 2011.

[11]L. Ferrer-Martí, B. Domenech, A. García-Villoria, and R. Pastor, "A MILP model to design hybrid windphotovoltaic isolated rural electrification projects in developing countries," European Journal of Operational Research, DOI: 10.1016/j.ejor.2012.11.018, vol. 226, no. 2, pp. 293-300, 2013.

[12]E. E. Gaona, C. L. Trujillo, and J. a. Guacaneme, "Rural microgrids and its potential application in Colombia," Renewable and Sustainable Energy Reviews, DOI: 10.1016/j.rser.2015.04.176, vol. 51, pp. 125-137, 2015.

[13]S. Ruiz Alvarez, A. Márquez Ruiz, and J. Espinosa Oviedo, "Optimal design of a diesel-PV-wind system with batteries and hydro pumped storage in a Colombian community," IEEE 6th International Conference on Renewable Energy Research and Applications ICRERA, DOI; 10.1109/ICRERA.2017.8191272, 2017. 
[14]S. R.- Álvarez, J. Patiño, A. Márquez, and J. Espinosa, "Optimal Design for an Electrical Hybrid Micro Grid in Colombia Under Fuel Price Variation,", International Journal of Renewable Energy Research, vol. 7, no. 4, 2017.

[15]K. Nikhil, M. K. Mishra, and S. Kotra, "Power management based on the operating conditions of grid, mircogrid and hybrid storage," 2015 Int. Conf. Renew. Energy Res. Appl. ICRERA 2015, pp. 1437-1441, 2015.

[16]S. Kotra and M. K. Mishra, "Energy management of hybrid microgrid with hybrid energy storage system," International Conference on Renewable Energy Research and Applications ICRERA, pp. 856-860, 2015.

[17]T. Bogaraj and J. Kanakaraj, "A Novel Energy Management Scheme using ANFIS for Independent Microgrid," International Journal of Renewable Energy Research., vol. 6, no. 3, 2016.

[18]S. Albert, "Solving Mixed Integer Linear Programs Using Branch and Cut Algorithm," 1999.

[19]A. Maleki and A. Askarzadeh, "Optimal sizing of a $\mathrm{PV} /$ wind/diesel system with battery storage for electrification to an off-grid remote region: A case study of Rafsanjan, Iran," Sustainable Energy Technologies and Assessments, DOI: 10.1016/j.seta.2014.04.005, vol. 7, pp. 147-153, 2014.

[20]N. M. Bellaaj, "Optimal Sizing Design Of An Isolated Microgrid Using Loss Of Power Supply Probability," 2015 6th International Renewable Energy Congress (IREC), DOI: 10.1109/IREC.2015.7110941, 2015.

[21] a Kaabeche, M. Belhamel, and R. Ibtiouen, "Optimal sizing method for stand-alone hybrid PV / wind power generation system," International Conference on Swarm, Evolutionary, and Memetic Computing, pp. 205-213, 2010.

[22]T. Van de Boom and B. De Schutter, Lectures on optimization fot systems and control, Delft Cent. 2004.

[23]Climate Challenges Market Solutions, "Precios CO2," Sistema europeo de negociación de CO2, 2015. [Online]. Available: http://www.sendeco2.com/es/. [Accessed: 23Nov-2016].
[24]D. Tobón Orozco and S. Agudelo Flórez, “Optimización de herramientas multiobjetivo para la toma de decisiones de inversión en sistemas aislados sostenibles de energía," PhD Propos., vol. 1, pp. 1-223, 2015.

[25]Oxfam, "Divide and Purchase: How land ownership is being concentrated in Colombia," p. 40, 2013. [Online]. Available: http://www.oxfam.org/sites/www.oxfam.org [Accessed: 23-Nov-2016].

[26]N. E. Gómez, “Energización de las zonas no interconectadas a partir de las energias renovables solar y eólica," Universidad Pontificia Javeriana, 2011.

[27]C. Sánchez, F. Rodriguez, E. Collante, and O. Simbaqueva, "Atlas de radiación solar de Colombia," HIMAT, Bogotá, Colomb., pp. 13-22, 1993.

[28]Instituto de Hidrología Meteorología y Estudios Ambientales, "Datos estadísticos meteorológicos de temperatura del aire y velocidad de viento en la superficie en el municipio de Unguía-Chocó.” Bogotá D.C., 2016.

[29]NASA, "NASA Surface meteorology and Solar Energy: HOMER Data," NASA Surface meteorology and Solar Energy, 2016. [Online]. Available: https://eosweb.larc.nasa.gov/cgi-bin/sse/homer.cgi. [Accessed: 23-Nov-2016].

[30]V. Graham and K. Hollands, "A time series model for Kt with application to global synthetic weather generation," Sol. Energy, vol. 40, no. 2, pp. 83-92, 1988.

[31]Columbia University, "Climate Data Library IRIDL," 2018. [Online]. Available: http://iridl.ldeo.columbia.edu/index.html?SetLanguage $=$ es. [Accessed: 18-Mar-2018].

[32]Instituto de Planificación y Promoción de Soluciones Energéticas para las Zonas No Interconectadas - IPSE, "Reporte de energía mensual para 2015 del municipio de Unguía-Chocó," 2016.

[33]S. Ruiz, "Metodología para el diseño de microrredes aisladas usando métodos de optimización numérica," Universidad Nacional de Colombia, 2017. 